\title{
STRUKTUR TINGKAT TROFIK KOMUNITAS IKAN DI WADUK WADASLINTANG KABUPATEN WONOSOBO, JAWA TENGAH
}

\section{TROPHIC LEVELS STRUCTURE OF FISH COMMUNITY IN WADASLINTANG RESERVOIR WONOSOBO REGENCY , CENTRAL JAVA}

\author{
Khoirul Fatah dan Susilo Adjie \\ Balai Penelitian Perikanan Perairan Umum, Palembang \\ Teregistrasi I tanggal: 05 Mei 2014; Diterima setelah perbaikan tanggal: 30 November 2015; \\ Disetujui terbit tanggal: 02 Desember 2015 \\ e-mail:khoirul75@gmail.com
}

\begin{abstract}
ABSTRAK
Waduk Wadaslintang memiliki potensi perikanan yang cukup besar baik perikanan tangkap maupun perikanan budidaya. Kegiatan penangkapan ikan di waduk Wadaslintang saat ini sudah cukup tinggi, yang akan berdampak langsung pada struktur komunitas ikan yang menyebabkan pergeseran pola hubungan antara pemangsa, mangsa atau pesaing pada berbagai tingkat trofik. Tujuan penelitian ini untuk mengetahui pola hubungan antar kelompok ikan berdasarkan tingkat trofik dari tingkat trofik terendah sampai kepada ikan karnivor, sehingga diperoleh gambaran peran kelompok ikan dalam komunitas. Penelitian ini dilaksanakan pada bulan April, Juni, September dan Nopember 2013 di perairan waduk Wadaslintang. Analisa data mencakup komposisi hasil tangkapan dan kebiasaan makan ikan serta tingkat trofik komunitas ikan. Analisis sidik ragam untuk mengetahui perbedaan antar tingkat trofik. Ikan contoh diperoleh dari nelayan dengan alat tangkap jaring, mulai dari ukuran $0,75-4,5$ inchi. Hasil penelitian diketemukan sebanyak 15 jenis ikan yang didominasi oleh ikan nila dengan persentase berat mencapai $56,45 \%$. Struktur komunitas ikan di perairan waduk Wadaslintang tersusun atas tiga kelompok tingkat trofik yaitu ikan patin, nila, tawes dan melem mempunyai jenjang trofik terendah $(<2,5)$, ikan bader dan brek mempunyai nilai jenjang trofik sedang $(2,5-3,49)$ dan ikan beong, betutu, palung dan lele mempunyai nilai jenjang trofik tertinggi $(>3,5)$. Kelompok ikan pada tingkat trofik rendah $<2,5$ sangat penting dalam menyokong komunitas ikan di perairan waduk Wadaslintang karena akan mempengaruhi kelompok ikan dengan tingkat trofik tinggi.
\end{abstract}

KATA KUNCI: Komposisi ikan, makanan ikan, tingkat trofik,waduk Wadaslintang

\begin{abstract}
Wadaslintang reservoirs was considered have high potential for fisheries and aquaculture. Fishing Activities in the Wadaslintang reservoir is currently quite high, which may gave a direct impact on the trophic levels structure of fish community and would change composition of predators, preys, and competitors on various trophik levels. The objective of research was focused on the pattern of relationship among trophic groups from the lowest level of trophic to the highest level of carnivorous fish, to find out the role of each fish group in the community. This research was carried out in April, June, September and November 2013 at Wadaslintang reservoir waters. The recorded data were analysed to find out the composition of the fish, feeding habits and trophic levels, and followed by statistical analysis of variance to evaluate the difference among trophic level. Fish samples obtained from a capture tool gillnets, ranging from size $0.75-4.5$ inches. The results shows that Wadaslintang Reservoir was habited by 15 species of fish where Nile Tilapiais is the dominance species with percentage weight is 56,45\%. The structure of fish communities in the water of the Wadaslintang reservoir composed of three groups, namely trophic level of sutchi catfish, nile tilapia, silver barb and nilem had the lowest trophic levels (<2.5), barb and javaen barb had value trophic level moderat (2.5-3.49) and catfish, marble goby, hampala barb and walking catfish had the highest trophic level values (>3.5). Fish group on trophic level $<2.5$ levels is very important group in supporting good community structure in Wadaslintang reservoir as a way to sustainability of populaion oh the other groups with higher trophic level.
\end{abstract}

KEYWORDS : Composition of fish, fish food, trophic level, Wadaslintang Reservoir

\section{PENDAHULUAN}

Waduk Wadaslintang terletak di Kabupaten Wonosobo Propinsi Jawa Tengah, berada pada ketinggian $700 \mathrm{~m}$ dpl, memiliki luas sekitar 1463 hektar dan kedalaman rata-rata \pm 33 meter dengan kedalaman maksimum Korespondensi penulis:

Balai Penelitian Perikanan Perairan Umum

Jl. Beringin No. 308, Mariana Palembang-Sumatera Selayan, 30763 mencapai 190 meter sehingga masuk dalam kategori waduk dalam (Adjie et al., 2013). Waduk Wadaslintang adalah waduk serbaguna berfungsi untuk pertanian, pariwisata, PLTA, pengendali banjir dan perikanan. Waduk Wadaslintang juga memiliki potensi perikanan yang cukup besar baik perikanan tangkap maupun perikanan budidaya 
(Anonimous, 2009), dan tergolong perairan yang subur (Purnomo et al., 2011).

Dari data dinas perikanan dan kehewanan Wonosobo (2012), produksi hasil tangkapan ikan di Waduk Wadaslintang dalam tiga tahun terakhir ini mengalami penurunan yaitu tahun 2009 (94.363 kg), tahun 2010 (85.672 $\mathrm{kg}$ ) dan tahun $2011(80.352 \mathrm{~kg})$. Penurunan hasil tangkapan ini akibat dari penangkapan ikan yang sudah cukup tinggi di waduk Wadaslintang. Penurunan hasil tangkapan ikan akan berdampak langsung terhadap komunitas ikan di waduk yang menyebabkan pergeseran pola hubungan antara pemangsa, mangsa atau pesaing pada berbagai tingkat trofik.

Tingkatan trofik menggambarkan tahapan transfer material atau energi dari setiap tingkat atau kelompok ke tingkat berikutnya, yang dimulai dengan produser primer, konsumer primer (herbivor), kemudian sekunder, tersier dan diakhiri dengan predator puncak. Pada dasarnya tingkat trofik (trophic level) merupakan urut-urutan tingkat pemanfaatan pakan atau material dan energi seperti yang tergambar oleh rantai makanan (food chain). Mc Clanahan \& Mangi (2004) menyatakan bahwa penangkapan dapat merubah kelimpahan mutlak dan relatif spesies sehingga merubah komposisi spesies dalam tingkat trofik dan bahkan merubah biomass relatif pada berbagai tingkat trofik. Sedangkan menurut Garisson \& Lingk (2000) dalam Lopez et.al. (2005), adanya penangkapan dapat merubah distribusi spasial dan kelimpahan ikan dan selanjutnya bepengaruh penting terhadap interaksi spesies dan struktur trofik pada umumnya.

Kegiatan penangkapan sangat potensial berpengaruh pada semua tingkatan trofik dalam ekosistem. Dengan demikian pendekatan tingkat trofik dapat digunakan untuk mengevaluasi kesehatan dan kondisi ekosistem, sehingga merupakan mata rantai awal yang penting dipertimbangkan untuk menjaga keberlanjutan sumberdaya perikanan. Dengan mengkaji struktur trofik akan diperoleh konsep pengelolaan sumberdaya perikanan yang mempertimbangkan kestabilan ekosistem. Penelitian ini bertujuan untuk mengetahui pola hubungan antar kelompok ikan berdasarkan tingkat trofik dari tingkat trofik terendah sampai kepada ikan karnivor, sehingga diperoleh gambaran peran kelompok ikan dalam komunitas.

\section{BAHANDANMETODE}

Penelitian ini dilakukan di waduk Wadaslintang, Jawa Tengah (Gambar 1), pada bulan April, Juni, September dan Nopember 2013. Pengumpulan data dilakukan dengan menggunakan metode survei lapangan dan laboratorium. Nelayan yang dipilih untuk mengoperasikan jaring adalah nelayan yang sudah berpengalaman dalam menangkap ikan lebih dari 12 tahun, jumlah nelayan yang mengoperasikan jaring sebanyak tiga orang. Contoh ikan diperoleh dari hasil tangkapan nelayan menggunakan jaring insang, dengan ukuran mata jaring mulai dari 0,754,5 inchi sebanyak masing-masing tiga pcs per ukuran per nelayan. Operasional jaring dilakukan di tepi waduk dengan posisi melintang pada kedalaman berkisar antara 2-5 meter. Masing-masing jenis ikan hasil tangkapan di catat beratnya (biomasa), jenis ikan diindentifikasi menggunakan buku Kottelat et al.(1993), lalu diukur panjang dan bobotnya, diambil isi perutnya dimasukkan dalam kantong plastik kemudian diawetkan dengan larutan formalin $4 \%$ dan diberi label. Pengamatan isi usus dilakukan di laboratorium biologi Balai Penelitian Perikanan Perairan Umum, Palembang. Jenis ikan makanan diidentifikasi menggunakan buku identifikasi dari Edmonson (1973), Needham \& Needham (1963).

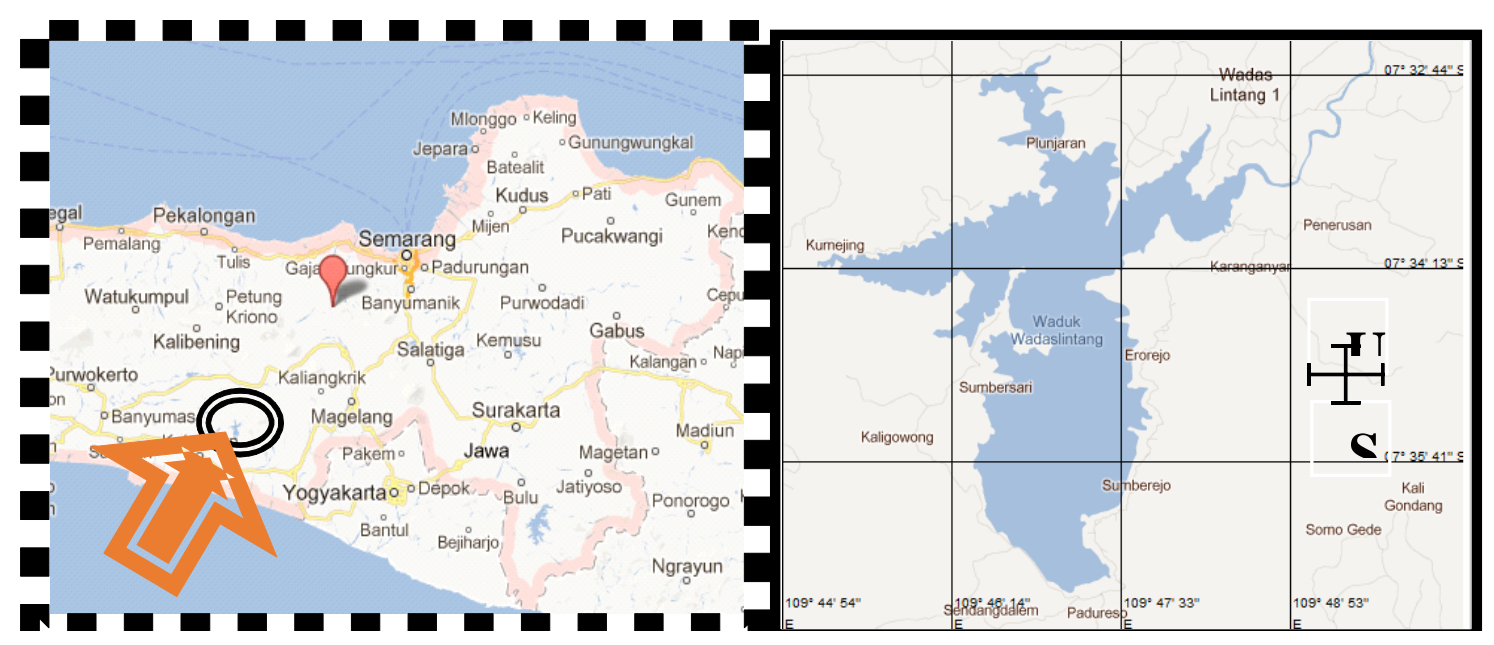

Gambar 1. Daerah lokasi penelitian waduk Wadaslintang, Jawa Tengah.

Figur 1. Wadaslintang reservoir research sites, Central Java. 
Kebiasaan makan ikan dianalisa menggunakan index of preponderance dirujuk dari Natarajan \& Jingran (1961) dalam Effendie (1979) persamaan sebagai berikut

$$
I P=\frac{V i x O i}{\sum V i \times \mathrm{Oi}} \times 100
$$

Keterangan :

$$
\begin{aligned}
\mathrm{Vi}= & \text { persentase volume satu macam makanan }(\%) \\
\mathrm{Oi}= & \text { persentase frekuensi kejadian satu macam } \\
& \text { makanan }(\%) \\
\sum \mathrm{Vix} \mathrm{Oi}= & \text { Jumlah } \mathrm{Vi} \times \text { Oi dari semua macam makanan } \\
& (\%) \\
\mathrm{IP}= & \text { Index of preponderance }(\%)
\end{aligned}
$$

Pengukuran status tingkat trofik menggunakan persamaan (Christensen \& Pauly (1992); Froese \& Pauly (2000) in Bozec et al., (2011):

$\mathrm{TL}_{\mathrm{i}}=1+\sum\left\{\left(\mathrm{T}_{\mathrm{ij}} \times \mathrm{I}_{\mathrm{pj}}\right) / 100\right\}$
Keterangan:

$\mathrm{TL}_{\mathrm{i}}=$ tingkat trofik kelompok ikan-i

$\mathrm{T}_{\mathrm{ij}}=$ tingkat trofik kelompok pakan ke-j

$\mathrm{I}_{\mathrm{pj}}^{\mathrm{ij}}=$ index of preponderance dari kelompok pakan ke-j

Perbedaan antar kelompok tingkat trofik dianalisa mengunakan analisa sidik ragam satu arah (Steel \& Tori, 1989).

\section{HASIL DAN BAHASAN \\ Hasil}

\section{Komposisi Jenis Ikan}

Berdasarkan data hasil tangkapan nelayan di waduk Wadaslintang menggunakan berbagai ukuran alat tangkap jaring mulai dari 0,75 - 4,5 inchi diketemukan 15 jenis ikan yang didominasi oleh famili Cyprinidae sebanyak 6 jenis (Tabel.1). Komposisi ikan hasil tangkapan nelayan menggunakan jaring insang tertera pada tabel 2 .

Tabel 1. Jenis-jenis ikan tertangkap dengan jaring di waduk Wadaslintang

Table 1. Fish species caught with gillnets in the Wadaslintang reservoir

\begin{tabular}{cccc}
\hline No & $\begin{array}{c}\text { Nama Lokal/Local } \\
\text { Name }\end{array}$ & Famili/Family & Nama Ilmiah/Scientific Name \\
\hline 1 & Nila & Cichlidae & Oreochromis niloticus \\
2 & Betutu & Eleotrididae & Oxyeleotris marmorata \\
3 & Brek & Cyprinidae & Systomus orphoides \\
4 & Palung & Cyprinidae & Hampala macrolepidota \\
5 & Gabus & Channidae & Channa striata \\
6 & Lele lokal & Clariidae & Clarias batrachus \\
7 & Bawal & Serrasalmidae & Colossoma macropomum \\
8 & Bader & Cyprinidae & Cyclocheilichthys enoplos \\
9 & Melem & Cyprinidae & Osteochillus vittatus \\
10 & Beong & Bagridae & Hemibagrus nemurus \\
11 & Tawes & Cyprinidae & Barbodes gonionotus \\
12 & Mujair & Cichlidae & Oreochromis mossambicus \\
13 & Wader & Cyprinidae & Puntius binotatus \\
14 & Patin & Pangasiidae & Pangasianodon hypophthalmus \\
15 & Gurame & Osphronemidae & Osphronemus gouramy \\
\hline
\end{tabular}


Tabel 2. Komposisi berat dan jumlah individu ikan tangkapan jaring insang di waduk Wadaslintang Table 2. Composition in wight and numbers of fish caught by gillnets inWadaslintang reservoir

\begin{tabular}{cllcc}
\hline No & $\begin{array}{c}\text { Nokal/Local } \\
\text { Name }\end{array}$ & \multicolumn{1}{c}{ Nama Ilmuah/Scientific Name } & $\begin{array}{c}\% \\
\text { Berat/Wight }\end{array}$ & $\begin{array}{c}\text { \% } \\
\text { Jumlah/Numbers }\end{array}$ \\
\hline 1 & Nila & Oreochromis niloticus & 56,45 & 57,12 \\
2 & Betutu & Oxyeleotris marmorata & 10,97 & 11,12 \\
3 & Brek & Systomus orphoides & 8,92 & 9,12 \\
4 & Palung & Hampala macrolepidota & 5,32 & 5,12 \\
5 & Bader & Cyclocheilichthys enoplos & 4,13 & 5,58 \\
6 & Melem & Osteochillus vittatus & 2,75 & 3,28 \\
7 & Tawes & Barbodes gonionotus & 2,42 & 2,82 \\
8 & Lele & Clarias batrachus & 1,92 & 1,92 \\
9 & Patin & Pangasianodon hypophthalmus & 1,62 & 0,91 \\
10 & Beong & Hemibagrus nemurus & 1,51 & 1,12 \\
11 & Wader & Puntius binotatus & 1,21 & 0,73 \\
12 & gurame & Osphronemus gouramy & 0,89 & 0,14 \\
13 & Mujair & Oreochromis mossambicus & 0,82 & 0,53 \\
14 & Bawal & Colossoma macropomum & 0,75 & 0,42 \\
15 & Gabus & Channa striata & 0,32 & 0,12 \\
\hline
\end{tabular}

Dari 15 jenis ikan yang tertangkap, hanya 10 jenis ikan yang di analisa kebiasaan makanan dan dianggap mewakili komunitas ikan di lokasi penelitian (Tabel 3).

\section{Kebiasaan Makanan Ikan}

Data hasil analisis makanan ikan (betutu, brek, lele, melem, nila, palung, beong, patin, tawes, dan bader), yang terdapat di waduk Wadaslintang selama penelitian disajikan pada tabel 4 .

\section{Tingkat Trofik Komunitas Ikan}

Hasil analisis tingkat trofik makanan dari sepuluh jenis ikan di waduk Wadaslintang memeperlihatkan bahwa ikan betutu mempunyai nilai tingkat trofik $(3,64)$, lele $(3,70)$, palung $(3,50)$, beong $(3,50)$, brek $(2,60)$, tawes $(2,10)$, bader $(2,50)$, patin (2), melem $(1,83)$, dan nila (2) (Tabel 5). Ikan betutu dan lele mempunyai nilai trofik paling tinggi sedangkan ikan melem terendah. Penentuan jenjang trofik makanan ikan menurut Nurhakim (2005).

Tabel3. Jenis-jenis ikan yang diukur Panjang - Bobot dan diperiksa isi saluran pencernaannya di Waduk Wadaslintang

Table 3. Fish species that measured lenght-weight and examined the contents of the digestive tract in Wadaslintang reservoir

\begin{tabular}{cllccc}
\hline No & $\begin{array}{c}\text { Nama Lokal/ } \\
\text { Local Name }\end{array}$ & \multicolumn{1}{c}{$\begin{array}{c}\text { Nama Ilmiah/ } \\
\text { Scientific Name }\end{array}$} & $\begin{array}{c}\text { Jumlah } \\
\text { Individu/ } \\
\text { Numbers }\end{array}$ & $\begin{array}{c}\text { Kisaran } \\
\text { Panjang } \\
(\text { Cm)/Long } \\
\text { Range }\end{array}$ & $\begin{array}{c}\text { Kisaran } \\
\text { Bobot/Weight } \\
\text { Range }\end{array}$ \\
\hline 1 & Betutu & Oxyeleotris marmorata & 47 & $8,6-41$ & $30-1144$ \\
2 & Brek & Systomus orphoides & 17 & $7,9-27,2$ & $28-224$ \\
3 & Lele & Clarias batrachus & 16 & $14,5-43,3$ & $45-698$ \\
4 & Melem & Osteochillus vittatus & 14 & $8,5-21,6$ & $13-114$ \\
5 & Nila & Oreochromis niloticus & 16 & $6,6-25,5$ & $28-346$ \\
6 & Palung & Hampala macrolepidota & 14 & $20,5-40,2$ & $332-886$ \\
7 & Beong & Hemibagrus nemurus & 14 & $15,2-39$ & $35,2-109$ \\
8 & Patin & Pangasianodon hypophthalmus & 17 & $14-37,2$ & $19-458$ \\
9 & Tawes & Barbodes gonionotus & 16 & $9,8-29$ & $25-368$ \\
10 & Bader & Cyclocheilichthys enoplos & & $9,4-24,5$ & $31-313$ \\
\hline
\end{tabular}


Tabel 4. Nilai indeks bagian terbesar makanan ikan di waduk Wadaslintang

Table 4. The index of preponderance of fish food in the Wadaslintang reservoir

\begin{tabular}{|c|l|c|c|c|c|c|c|c|c|}
\hline \multirow{2}{*}{ No } & $\begin{array}{l}\text { Nama Lokal/ } \\
\text { Local Name }\end{array}$ & \multicolumn{7}{|c|}{ Komposisi Makanan/Diet Composition (\%) } \\
\cline { 2 - 10 } & Ikan & Udang & Keong & Serangga & Pitoplankton Tanaman air Detritus & Pelet \\
\hline 1 & Betutu & 66.58 & 14.29 & 19.13 & & & & & \\
\hline 2 & Brek & & 15 & & 30 & 25 & 30 & \\
\hline 3 & Lele & 67.37 & 32.01 & 0.11 & 0.04 & & 0.4 & 0.07 & \\
\hline 4 & Melem & & & & & 56 & 14 & 30 & \\
\hline 5 & Nila & & & & & 40 & 60 & & \\
\hline 6 & Palung & 50 & 30 & 20 & & & & & \\
\hline 7 & Beong & 50 & 50 & & & & 25 & 27.5 & 47.5 \\
\hline 8 & Patin & & & & & & 60 & 10 & \\
\hline 9 & Tawes & & & 10 & & 20 & 50 & & \\
\hline 10 & Bader & & & & 50 & & & \\
\hline
\end{tabular}

Tabel 5. Nilai jenjang trofik level makanan ikan di waduk Wadaslintang

Table 5. Value trophic levels of fish meal in the Wadaslintang reservoir

\begin{tabular}{cccc}
\hline No & $\begin{array}{c}\text { Nama Lokal/Local } \\
\text { Name }\end{array}$ & Nilai Trofik/Thropic Value & Jenjang trofik/Trophic Level \\
\hline 1 & Betutu & 3,64 & Tinggi \\
2 & Lele & 3,70 & Tinggi \\
3 & Palung & 3,50 & Tinggi \\
4 & Beong & 3,50 & Tinggi \\
5 & Brek & 2,60 & Sedang \\
6 & Bader & 2.50 & Sedang \\
7 & Tawes & 2.10 & Rendah \\
8 & Patin & 2.00 & Rendah \\
9 & Melem & 1.83 & Rendah \\
10 & Nila & 2.00 & Rendah \\
\hline
\end{tabular}

\section{Inter-Relasi Trofik}

Berdasarkan kebiasaan makanan dan tingkat trofik yang telah dianalisis, maka dapat dibuat dugaan inter- relasi atau keterkaitan diantara masing-masing tingkat trofik sehingga membentuk aliran seperti tergambar dalam Gambar 2.

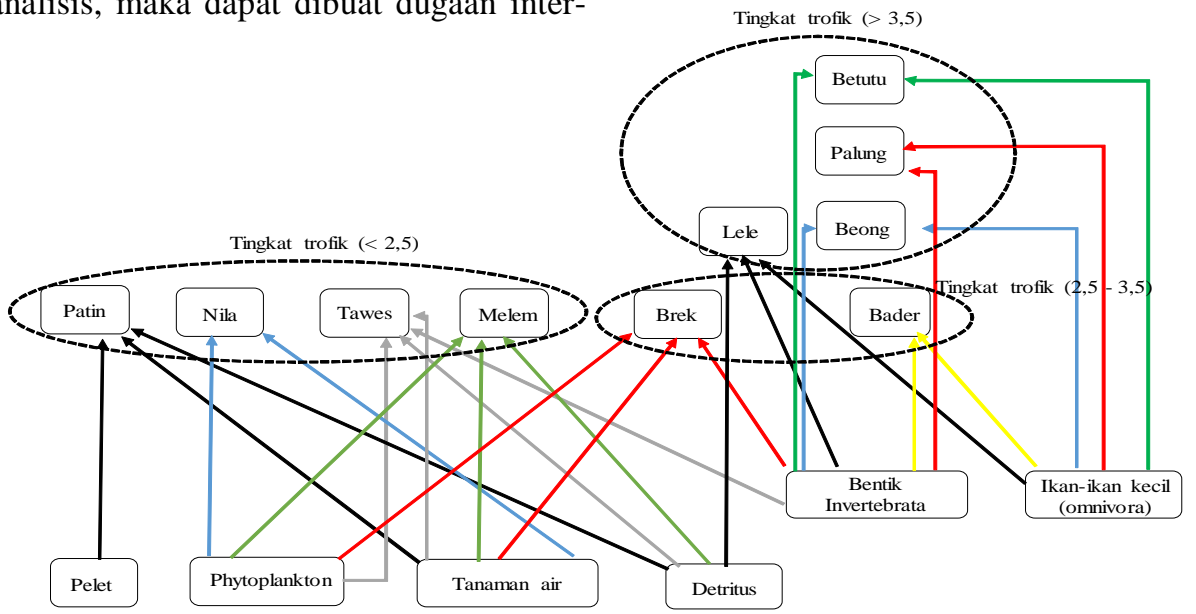

Keterangan : Ikan kecil omnivora adalah patin, nila, tawes, melem, bader dan brek

Description: small omnivorous fish are sutchi catfish, nile tilapia, silver barb, nilem, barb and javaen barb

Gambar 2. Perkiraan inter-relasi trofik komunitas ikan di lokasi penelitian.

Figure 2. Estimated trophic inter relationships of fish communities in the study site. 


\section{Bahasan \\ Komposisi Jenis Ikan}

Jenis ikan yang paling banyak tertangkap di waduk Wadaslintang Berdasarkan persentase berat didominasi oleh ikan nila sebesar $56,45 \%$, disusul oleh betutu sebesar $10,97 \%$ dan brek 8,92 \%, sedangkan berdasarkan persentase individu juga didominasi oleh ikan nila sebesar $57,12 \%$ disusul betutu sebesar $11,12 \%$ dan brek sebesar $9,12 \%$. Hal ini sesuai dengan hasil pernyataan Purnomo et.al., (2011), bahwa ikan nila dan ikan betutu mendominasi hasil tangkapan jaring insang di waduk Wadaslintang.

\section{Kebiasaan Makanan Ikan}

Analisis isi usus terhadap sepuluh jenis ikan di waduk Wadaslintang memeperlihatkan bahwa ikan-ikan tersebut memanfaatkan sumber daya makanan alami yang beragam yaitu ikan, udang, keong, serangga, fitoplankton, tanaman air, detritus dan pelet (pelet berasal dari sisa pakan ikan yang terlepas dari keramba budidaya di waduk Wadaslintang). Tingginya ragam makanan ini menunjukkan bahwa sumberdaya makanan tersebut di lokasi penelitian cukup melimpah (Al-Zibdah 2009).

Macam pakan ikan dapat dibedakan dalam 3 kategori, yaitu pakan utama, pelengkap dan tambahan (Nikolsky, 1963). Pakan utama adalah jenis pakan yang mempunyai nilai Index of preponderance (IP) lebih besar dari $40 \%$, pakan pelengkap antara 4 s/d $40 \%$ dan pakan tambahan kurang dari $4 \%$ (Noor, 2001). Komunitas makanan ikan di waduk Wadaslintang terbagi 7 kelompok ikan yang berbeda berdasarkan kebiasaan makanannya, kelompok pertama (tiga jenis ikan yang memanfaatkan ikan sebagai makanan utama yaitu ikan betutu, lele dan palung), kelompok kedua (satu jenis ikan yang memanfaatkan ikan dan udang sebagai makanan utama yaitu beong), kelompok ketiga (dua jenis ikan yang memanfaatkan serangga dan tanaman air sebagai makanan utama yaitu ikan bader dan brek), kelompok keempat (satu jenis ikan yang memfaatkan fitoplankton dan tanaman air sebagai makanan utama yaitu ikan nila), kelompok kelima (satu jenis ikan yang memanfaatkan fitoplankton sebagai makanan utama yaitu melem), kelompok keenam (satu jenis ikan yang memanfaatkan tanaman air sebagai makanan utama yaitu ikan tawes) dan kelompok ketujuh (satu jenis ikan yang memanfaatkan pelet sebagai makanan utama yaitu ikan patin). Ikan patin di waduk wadaslintang merupakan ikan introduksi atau ikan teberan yang dilepaskan oleh dinas perikanan Wonosobo tahun 2007. Ikan tersebut tumbuh/berkembang baik di waduk Wadaslintang. Ikan patin memakan pelet karena ikan tersebut memanfaatkan sisa pakan yang terlepas dari kolam keramba ikan budidaya dan ikan patin banyak menggumpul di sekitar keramba.

\section{Struktur Tingkat Trofik Komunitas Ikan}

Analisis tingkat trofik terhadap komunitas ikan rentang nilai mulai 1,8 hingga 3,70. Ragam tingkat trofik ikan omnivora berada pada rentang tingkat trofik yang beragaman yaitu $<2,5$, sedangkan ikan karnivora mempunyai nilai tingkat trofik yang rentangnya tidak beragam yaitu 3,5 - 3,64 hal ini disebabkan ikan karnivora bersifat selektif/sempit dalam memilih makanan yaitu suka makan daging saja. Sedangkan ikan omnivora bersifat luas atau beragam dalam memilih makanan. Hal ini sesuai dengan pernyataan Sriati (2012) bahwa ikan ominvora mempunyai nilai tingkat trofik lebih beragam di bandingkan ikan karnivora.

Dalam menganalisis struktur trofik, tingkat trofik dikelompokkan menjadi tiga kelompok yaitu (jenjang trofik rendah) <2,5, (jenjang trofik sedang) 2,5 - 3,49 dan (jenjang trofik tinggi) $>3,5$ (Nurhakim, 2005). Jenjang trofik rendah adalah ikan omnivora cendrung bersifat herbivora, jenjang trofik sedang adalah ikan omnivora cenderung bersifat karnivora atau herbivora, jenjang trofik tinggi adalah ikan karnivora/predator. Pengelompokan tingkat trofik ini dimaksudkan untuk mengetahui kelompok tingkat trofik dalam komunitas ikan. Ikan di lokasi penelitian mempunyai tiga kelompok tingkat trofik yaitu ikan patin, nila, tawes dan melem mempuyai jenjang trofik terendah, ikan bader dan brek mempunyai nilai jenjang trofik sedang dan ikan beong, betutu, palung dan lele mempunyai nilai jenjang trofik tertinggi. Didapatkan tiga kelompok tingkat trofik ikan dilokasi penelitian disebabkan jenis ikan yang ada dilokasi penelitian dalam jumlah sedikit, dan rendahnya jumlah kelompok ikan dalam jenjang trofik menunjukkan belum ada kompetisi yang kuat terhadap sumberdaya makanan. Hal ini sesuai dengan pernyataan Nurhakim (2005) tinggi dan rendah kelompok ikan yang ada dalam jenjang trofik menunjukkan adanya kompetisi terhadap sumber daya makanan, makin rendah jumlah kelompok ikan yang ada dalam jenjang trofik maka kompetisi makin lemah terhadap sumberdaya makanan. Hal ini dapat dijadikan petunjuk adanya keseimbangan tingkat trofik ikan terhadap keseluruhan ekosistem waduk Wadaslintang. Dengan demikian pengkajian tentang jenjang trofik di suatu perairan dapat digunakan untuk menganalisis status sumberdaya perikanan.

Hasil pengelompokan tingkat trofik juga menunjukkan bahwa jumlah persentase berat ikan pada trofik rendah $(<$ $2,5)$ terdiri dari ikan nila, tawes, melem dan patin yang mempunyai nilai paling tinggi diantara kelompok tingkat trofik lainnya yaitu 63,24\% yang dominasi oleh ikan nila $56,45 \%$ (Tabel 2). Hal ini terjadi karena tingginya penangkapan ikan pada jenjang trofik diatasnya (pemangsa), sehingga ikan pada trofik level bawah dapat berkembang dengan baik dan didukung dengan tingkat 
reproduksi yang tinggi dan mudah adaptasi terhadap lingkungan yang kurang baik. Meningkatnya persentase ikan pada trofik level bawah diduga akibat intensitas penangkapan yang tinggi dari pemangsanya (Jennings \& Polunin 1997; Urene 2010). Jenis ikan pemangsa di waduk Wadaslintang yang berperan dalam menyokong komunitas ikan adalah ikan betutu, dan ikan ini merupakan target penangkapan nelayan karena memiliki nilai ekonomis tinggi sebagai ikan konsumsi. Hal ini juga didukung dengan hasil tangkapannya menduduki urutan kedua setelah ikan nila. Sedangkan jumlah persentase berat ikan pada trofik sedang $(2,5-3,49)$ terdiri dari ikan brek dan bader yang mempunyai nilai paling rendah yaitu mempunyai nilai 13,05 $\%$ yang didominasi oleh ikan brek 8,92\% (Tabel 2). Lebih rendahnya persentase berat ikan pada kelompok tingkat trofik sedang $(2,5-3,49)$ kemungkinan disebabkan oleh beberapa hal, yaitu penangkapan, perubahan lingkungan, dan tidak efisiennya transfer energi dalam bentuk makanan diantara komunitas ikan di trofik level tersebut. Sebagaimana dikemukakan oleh Effendie (1997), bahwa ikan dapat merubah kebiasaan makanannya ketika terjadi perubahan lingkungan. Kemungkinan yang terjadi adalah, sebagian dari jenis-jenis ikan pada kelompok tingkat trofik ini merubah kebiasaan makanannya menjadi herbivor sejati atau karnivor. Hal ini merupakan suatu indikasi adanya perubahan lingkungan di lokasi penelitian sehingga sumberdaya makanan berubah dan lebih jauh merubah kebiasaan makanan jenis-jenis ikan tertentu. Sebaliknya tingginya persentase berat ikan pada kelompok tingkat trofik rendah $(<2,5)$ menunjukkan bahwa jenisjenis ikan pada kelompok tingkat trofik ini mampu memanfaatkan sumberdaya makanan yang tersedia dengan sangat baik. Jenis-jenis ikan seperti ini pada umumnya memiliki luas relung makanan yang tinggi tersaji pada gambar 3, dan mampu beradaptasi dengan baik terhadap perubahan sumberdaya makanan. Menurut Crowder et.al., (1981) bahwa ikan yang memiliki relung yang luas menunjukkan kesuksesan keberadaannya di perairan. Sedangkan memurut Nontji (2006) bahwa semakin rendah tingkat trofik akan semakin kecil energi yang dibutuhkan untuk memperoleh makanannya sehingga dapat tumbuh lebih banyak.

Distribusi ikan per kelompok tingkat trofik dianalisis menggunakan analisa sidik ragam satu arah. Hasilnya menunjukkan bahwa terdapat tidak ada perbedaan distribusi ikan antar kelompok tingkat trofik (Tabel 5). Kelompok tingkat trofik rendah $(<2,5)$ tidak berbeda nyata dengan kelompok tingkat trofik sedang $(2,51-3,5)$ dan tidak berbeda nyata dengan kelompoktingkat trofiktinggi(> 3,50). Hal ini menunjukkan bahwa belum ada kompetisi yang kuat dalam sumberdaya makanan antar kelompok tingkat trofik dan antar tingkat trofik.

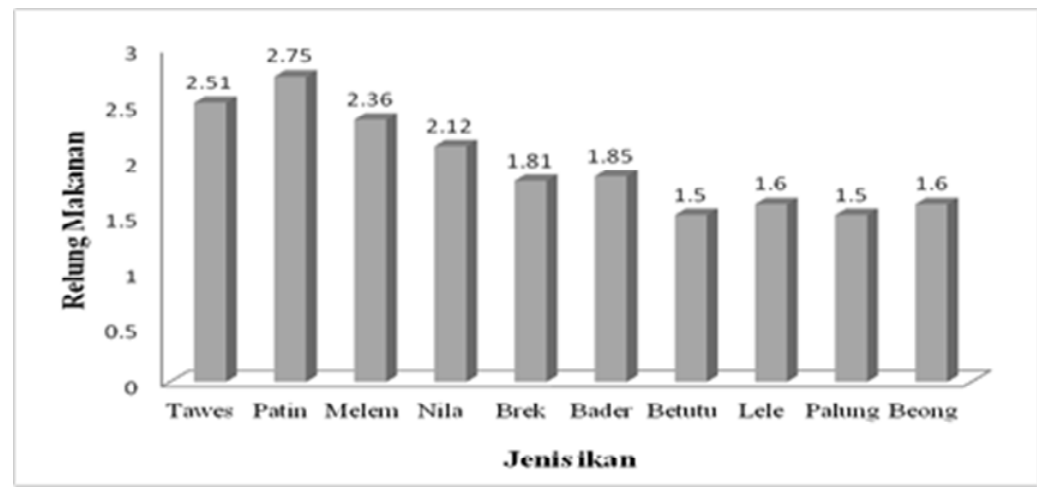

Sumber: Adjie et.al.,(2013)

Gambar 3. Luas relung makanan beberapa jenis ikan di waduk Wadaslintang.

Figure 3. Size niche food of some fish species in the Wadaslintang reservoir.

Tabel 6. Hasil analisis ragam tidak ada perbedaan biomasa ikan berdasarkan kelompok tingkat trofik Table 6. $\quad$ Results of variance analysis was not difference in fish biomass based on group trophic level

\begin{tabular}{lccccc}
\hline \multicolumn{1}{c}{ Keragaman/Diversity } & $\begin{array}{c}\text { Jumlah } \\
\text { kuadrat }\end{array}$ & Derajat bebas & $\begin{array}{c}\text { Jumlah } \\
\text { kuadrat }\end{array}$ & F & Sig. \\
\hline Diantara kelompok & 489.68 & 2 & 244.84 & 0.86 & 0.46 \\
Didalam Kelompok & 1998.37 & 7 & 285.48 & & \\
Total & 2488.05 & 9 & & & \\
\hline
\end{tabular}

Sig $(0.46)>0.05, F(0,86)$ mendekati 1, Terdapat kesamaan antar kelompok tingkat trofik 


\section{Inter-Relasi Trofik}

Komponen tingkat trofik terendah di lokasi penelitian terdiri dari fitoplankton, detritus, tanaman air dan pelet. Tanda panah pada gambar 2 menunjukkan perpindahan energi melalui hubungan makan - memakan seperti yang tergambar dalam rantai makanan. Dalam struktur trofik yang tergambar dalam aliran tersebut, keberadaan jenis ikan omnivora (kelompok ikan-ikan kecil yang berada pada tingkat trofik rendah) sangat penting untuk mendukung keberadaan ikan pada tingkat trofik atas (jenis-jenis ikan karnivora). Jenis ikan ominivora yang bersifat herbivora khususnya ikan nila merupakan ikan yang berperan penting dalam mengontrol populasi fitoplankton yang dapat mengakibatkan blooming di perairan waduk Wadaslintang. Sedangkan keberadaan ikan karnivora penting untuk mempertahakan keseimbangan komunitas agar tidak terjadi penurunan rantai makanan.

Berdasarkan hasil penelitian ini maka upaya pengelolaan sumberdaya ikan di perairan waduk Wadaslintang adalah pengaturan penangkapan terutama terhadap jenis ikan nila (omnivora yang cendrung bersifat herbivora), dan penangkapan terhadap jenis-jenis ikan ikan betutu (karnivora). Kedua ikan ini mendominasi dari total hasil tangkapan nelayan dan berperan penting dalam menyokong komunitas ikan di waduk Wadaslintang, karena ikan nila berperan penting dalam mengontrol populasi fitoplankton, sedangkan ikan betutu berperan penting untuk mempertahakan keseimbangan komunitas agar tidak terjadi penurunan rantai makanan. Disamping itu juga perlu diperhatikan pengaturan jenis dan ukuran alat tangkap, pengaturan area penangkapan dan pengaturan waktu penangkapan sebab ini akan mengurangi populasi dan produksi ikan di waduk wadaslintang. Penerapan pengelolaan penangkapan yang konsisten dalam jangka waktu yang panjang telah terbukti meningkatkan produksi ikan (Tamaki 2004).

\section{KESIMPULAN}

Struktur komunitas ikan di perairan waduk Wadaslintang tersusun atas tiga kelompok tingkat trofik yaitu ikan patin, nila, tawes dan melem mempunyai jenjang trofik terendah $(<2,5)$, ikan bader dan brek mempunyai nilai jenjang trofik sedang $(2,5-3,49)$ dan ikan beong, betutu, palung dan lele mempunyai nilai jenjang trofik tertinggi $(>3,5)$. Kelompok ikan pada tingkat trofik rendah $<2,5$ sangat penting dalam menyokong komunitas ikan di perairan waduk Wadaslintang karena akan mempengaruhi kelompok ikan dengan tingkat trofik tinggi. Dan rendahnya jumlah kelompok ikan dalam jenjang trofik menunjukkan belum ada kompetisi yang kuat terhadap sumberdaya makanan.

\section{PERSANTUNAN}

Tulisan ini merupakan kontribusi dari kegiatan hasil Penelitian Perikanan Berbasis Budidaya (Culture-Based Fisheries, $C B F$ ) di Perairan waduk Wadaslintang Provinsi Jawa Tengah. 2013, di Balai Penelitian Perikanan Perairan Umum-Mariana, Palembang.

\section{DAFTAR PUSTAKA}

Adjie, S., K. Fatah., S. Aprianti., A. Bintoro \& S. Gautama. 2013. Penelitian Perikanan Berbasis Budidaya (CultureBased Fisheries, $C B F)$ di Perairan waduk Wadaslintang Kabupaten Wonosobo Jawa Tengah. Laporan Teknis Penelitian. Balai Penelitian Perikanan Perairan Umum. Palembang: 125 hal.

Al-Zibdah M \& N Kan'an. 2009. Aspects of Growth, Reproduction, and Feeding Habit of Three Pomacentrid Fish From Gulf of Aqaba, Jordan. Jordan Journal of Biological Sciences. 2(3):119-128.

Anonimous. 2009. Indonesia fisheries statistic index 2009. Ministry of Marine Affairs and Fisheries. Japan International Cooperation Agency. 154p

Bozec YM, J Ferraris, D Gascuel, and M Kulbicki. 2011. The Trophic Structure Of Coral Reef Fish Assemblages:"Trophic Spectra” As Indicators Of Human Disturbances: 132p.

Christensen V \& D Pauly. 1992. Ecopath II-a Software for Balancing Steady-State Ecosystem Models and Calculating Network Characteristics. Ecological Modelling 61: $169-185$.

Crowder, L.B., J.J. Magnuson \& S.B. Brandt. 1981. Complementarity in the use of food and thermal habitat by lake Michigan Fishes. Can. J. Fish. Aquat. Sci.38 : $662-668$

Dinas Kehewanan dan Perikanan Kabupaten Wonosobo, 2012. Laporan singkat Pengelolaan Perikanan di Waduk Wadaslintang: 20 hal.

Edmonson, W. T. 1973. Fresh Water Biology. Second Edition. University of Washington. Seattle: 147p

Effendie, M.I. 1979. Metode Biologi Perikanan. Yayasan Dewi Sri. Bogor: 112 p.

Effendie, M. I. 1997. Metoda Biologi Perikanan. Fakultas Perikanan IPB. Bogor. Yayasan Agromedia. Bogor: 112 hal. 
Jennings S \& NVC Polunin. 1997. Impacts of Predator Depletion by Fishing on the Biomass and Biversity of Non-target Reef Fish Communities. Coral Reefs 16: 71-82.

Lo'pez AS, D Mouillot, TD Chi and JR Miranda. 2005. Ecological Indicators Based on Fish Biomasss Distribution along Trophic Levels: an Application to the Terminos Coastal Lagoon, Mexico. ICES Journal of Marine Science 62: 453 - 458.

Mc Clanahan TR \& SC Mangi. 2004. Gear-based Management of a Tropical Artisanal Fishery Based on Spesies Selectivity and Capture Size. Fisheries Management and Ecology 11: 51-60

Needham, J. G. \& P. R. Needham. 1963. A Guide to the Study of Freshwater Biology. Constable \& Co. Ltd. London: $112 \mathrm{p}$.

Nikolsky, G.V. 1963. The Ecology of Fishes. Academic Press. New York: 352p.

Nontji A. 2006. Tiada Kehidupan di Bumi Tanpa Keberadaan Plankton. LIPI. Pusat Penelitian Oseanografi. Jakarta: 248 hal.

Noor, A. 2001. Makanan Ikan Belanak (Mugil dussumieri) di Perairan Ujung Pangkah. Jawa Timur. Skripsi. Departemen Manajemen Sumberdaya Perairan. Fakultas Perikanan dan Ilmu Kelautan. Institutut Pertanian Bogor : 48 hal.
Nurhakim S. 2005. Marine Fisheries Resources of the North Coast of Central Java: An Ecosystem Analysis. In World Fish Center Conference Proceedings. 67:1.

Purnomo, K., E.S Kartamihardja., A. Warsa., D.A. Hedianto \& S. Romdon. 2011. Penelitian Potensi Sumberdaya Ikan Untuk Pengembangan Perikanan Tangkap Berbasis Budidaya (Culture-Based Fisheries, CBF) Di Provinsi Jawa Tengah (waduk Sempor, Penjalin dan Wadaslintang) dan Daerah Istimewa Yogyakarta (waduk Sermo). Balai Penelitian Pemulihan dan Konservasi Sumberdaya Ikan. Badan Penelitian dan Pengembangan Kelautan dan Perikanan. Kementerian Kelautan dan Perikanan: 88 hal.

Steel, R.G.B \& J.H. Tori. 1989. Prinsip dan Prosedur Statistik. Suatu Pendekatan Biometrik. Gramedia. Jakarta: 663 hal.

Sriati. 2012. Struktur trofik dan biologi populasi ikan di perairan pulau semak daun kepulauan seribu. Disertasi. Program Pasca Serjana. Program Studi Manajemen Sumberdaya Perairan. Fakultas Perikanan. Institut Pertanian Bogor: 115p.

Tamaki,Y. 2004. Fisheries Management of Sandfish in Akita Prefecture. IIFET Japan Proceedings.67:40.

Urena HM. 2009. Towards an Ecosystem Approach for Non-Target Reef Fishes: Habitat Uses and Population Dynamics of South Florida Parrotfishes (Perciformes: Scaridae). Scholarly Repository Open Access Dissertations Electronic Theses and Dissertations. University of Miami: 146p. 